\title{
A Randomized Clinical Trial of Peak Flow versus Symptom Monitoring in Older Adults with Asthma
}

\author{
A. Sonia Buist, William M. Vollmer, Sandra R. Wilson, E. Ann Frazier, and Arthur D. Hayward \\ Oregon Health and Science University, Portland; Center for Health Research, and Northwest Permanente, Kaiser Permanente Northwest, \\ Portland, Oregon; and Palo Alto Medical Foundation Research Institute, Palo Alto, California
}

\begin{abstract}
Objective: To determine whether peak flow monitoring has value above and beyond symptom monitoring when used as part of an asthma management plan.

Methods: From a large managed-care organization, 296 adults, aged 50-92 yr, were recruited and randomly assigned in equal numbers to either use of symptoms or peak flow rate (twice daily or "as needed") for asthma monitoring, and monitored every 6 mo for $2 \mathrm{yr}$. Interventions were delivered in four 90-min small-group classes and included a personalized action plan and coaching in proper use of asthma inhalers.

Results: We found no significant differences between peak flow rate and symptom monitoring, or between twice-daily and as-needed peak flow monitoring in the primary or secondary study outcomes: health care utilization (acute, nonacute, or total asthma visits), Asthma Quality-of-Life Questionnaire (AQLQ) scores, and lung function. AQLQ scores and prebronchodilator $\mathrm{FEV}_{1}$ increased significantly for both groups between baseline and 6 mo (AQLQ: mean, 0.4 units; $95 \%$ confidence interval, $0.3,0.5 ; \mathrm{p}<0.0001 ; \mathrm{FEV}_{1} \%$ predicted: mean, $4 \%$ ). Inhaler technique improved substantially in both groups.

Conclusions: Peak flow monitoring has no advantage over symptom monitoring as an asthma management strategy for older adults with moderate-severe asthma when used in a comprehensive asthma management program. Improved outcomes in both groups suggest that understanding proper medication use, regular monitoring of asthma status, and understanding how to respond to changes are of primary importance.
\end{abstract}

Keywords: health care utilization; lung function; quality of life; self-management

Most asthma guidelines recommend patient education and informed self-management as key components of successful asthma management, and a sizable body of literature supports this recommendation (1-9). There is strong evidence that education focused on improving patient self-management improves asthma outcomes for adults, whereas programs that merely impart information do not achieve behavior change and are not as successful in improving outcomes (10).

The National Asthma Education and Prevention Program's (NAEPP) Expert Panel 2 Report (EPR-2), published in 1997 (1), emphasized the importance of providing patients with a written asthma action plan based on signs and symptoms and/ or peak flow monitoring (PFM), and noted that this is especially

(Received in original form October 13, 2005; accepted in final form August 21, 2006) Supported by the National Heart, Lung, and Blood Institute (grant 1-RO1HL52598).

Correspondence and requests for reprints should be addressed to A. Sonia Buist, M.D., Oregon Health \& Science University, Mail Code UHN 67, 3181 SW Sam Jackson Park Road, Portland, OR 97239. E-mail: buists@ohsu.edu

This article has an online supplement, which is accessible from this issue's table of contents at www.atsjournals.org

Am J Respir Crit Care Med Vol 174. pp 1077-1087, 2006

Originally Published in Press as DOI: 10.1164/rccm.200510-1606OC on August 24, 2006 Internet address: www.atsjournals.org

\section{AT A GLANCE COMMENTARY}

Scientific Knowledge on the Subject

Although peak flow monitoring is recommended in treatment guidelines, there have been no studies to determine whether peak flow monitoring has value above and beyond symptom monitoring when used as part of an asthma management plan for older adults.

What This Study Adds to the Field

Peak flow monitoring had no advantage over symptom monitoring as an asthma management strategy for older adults with moderate-to-severe asthma.

important for patients with moderate-to-severe asthma or a history of exacerbations. The EPR-2 also recommended that all patients with moderate-severe asthma should learn how to monitor their peak flow and have a peak flow meter at homerecommendations that were upheld in the 2002 EPR Update on Selected Topics (11). Despite these clear recommendations, only a small proportion of patients with asthma have a peak flow meter (12), and an even smaller proportion use one regularly (12-18). Physicians seem uncertain of the role of PFM and of the importance of their patients' adherence to this routine (19).

The primary argument in favor of PFM is that it provides an objective assessment of lung function, as emphasized in the EPR 2002 update (11). Proponents argue that such monitoring enhances clinician-patient communication and thereby increases patient and caregiver awareness of disease status and control. By contrast, reliance on symptom monitoring (SM) could be misleading, because many patients have difficulty subjectively assessing their degree of airflow obstruction (20-22).

Despite the cogency of the arguments in favor of its use, the literature supporting the utility of PFM is limited. Studies showing a benefit from PFM have typically compared it with usual care (4-7), so its effects cannot be separated from those of other effects of the asthma education that usually accompany instruction in PFM (10). Five studies have directly compared SM and PFM (3, 8, 23-25). However, four of the five $(3,8,23$, 24) had limited power to detect treatment control differences, and none specifically targeted older patients. The one with sufficient power to detect treatment control differences was carried out in children aged 7 to $14 \mathrm{yr}$ (25), and found that knowledge of peak flow measurements did not enhance self-management, even during exacerbations.

The present randomized controlled study was designed to test the hypothesis that PFM in addition to SM would be superior to SM alone as a management tool in older adults with moderatesevere asthma when used as part of a comprehensive asthma management plan in terms of health care utilization (HCU), health-related quality of life, and lung function. Older adults 
with moderate-severe asthma were of particular interest because peak flow variability decreases with the fixed airflow obstruction that tends to develop as a function of asthma-related airway remodeling, as a result of cigarette smoking, and with treatment with inhaled antiinflammatory drugs (26).

Some of the results of this study have been previously reported in the form of abstracts (27-29).

\section{METHODS}

Additional detail on methods is provided in the online supplement.

\section{Study Population and Randomization}

The study population consisted of 296 adults, aged 50 to $92 \mathrm{yr}$, recruited from a large managed-care organization. All reported physiciandiagnosed asthma and had medication use suggestive of moderate-tosevere asthma (1). None was using a peak flow meter. Screening criteria included bronchodilator reversibility ( $>8 \%$ of baseline $\left.\mathrm{FEV}_{1}[30]\right)$ and demonstrated ability to keep a daily symptom diary.

After baseline data collection, patients were randomized in equal numbers to either SM or PFM interventions, and within the latter group, equally to twice-daily PFM or "as needed" monitoring. Because the study was not designed to determine whether asthma education and PFM were superior to usual care, there was no need for a nonintervention control group. The fact that the control group received education about asthma that was comparable to what was provided to the peak flow rate group and the fact that the control subjects were taught how to monitor changes in their symptoms were essential to obtain a clear answer to the question of primary interest in this study, which was the effectiveness of the specific strategy of monitoring using a peak flow monitor, specifically for older adults. Treatment assignments were randomly generated and distributed by computer in blocks of various sizes to ensure balance across treatment groups over time. Assignments were also stratified by age. Clinic staff who collected outcome data were blinded to treatment arm, and separate staff applied the randomization procedure and conducted the interventions. Study staff were monitored by clinic supervisors to ensure that blinding was maintained; however, there was no formal evaluation of the success of participant and staff blinding.

The study was designed to have $85 \%$ power to detect a mean difference of 0.5 acute care visits between the PFM and SM groups during the 2-yr follow-up period, with a total of $n=268$ (134/group). The power to detect a 0.5 -unit mean difference in the Juniper quality-oflife scale between the PFM and SM groups with $n=268$ exceeded $98 \%$.

\section{Intervention}

The interventions consisted of four 90-min small-group classes (Figure 1) and included development of a personalized action plan and review of the subjects' asthma diaries, which they were encouraged to share with their physicians. All patients were instructed in proper use of metered dose inhalers (MDIs) and were individually coached using a skill checklist (Figure 2). Coaching continued until the patient correctly demonstrated at least seven of the eight steps on the checklist, including all five steps critical to maximal deposition of active medication in the airways (Items 1, 2, 5, 6, and 7) (31, 32). In subsequent sessions, participants again demonstrated their technique and were given additional coaching as needed.

Interventionists also met with participants semiannually to review MDI and peak flow technique, review daily diaries, and discuss participants' action plans. In between these meetings, they phoned participants quarterly to review diaries and answer questions. A sample diary sheet

\section{Session 1}

Introduction and overview of the Peak Flow program

Understanding asthma

Pathophysiology

Symptoms

Early warning signs

How and why to monitor your asthma

Symptom Monitoring (SM)

or

Symptom plus Peak Flow Rate Monitoring (PFM, either BID or PRN)

Proper use of metered dose inhalers (MDIs)

Diary "homework"

\section{Session 2}

Asthma diaries and the Asthma Action Plan

Review of homework diaries

[Determination of "best" peak flow rate - PFM version only, either BID or PRN]

Asthma management "zones"

Introduction of the Asthma Action Plan

Stress and asthma management

Preventive and symptomatic relief medications

Review of peak flow meter use (PFM version only, either BID or PRN)

Review of MDI technique

"Homework"

\section{Session 3}

Medications

Review of MDI technique

Taking preventive medications according to schedule

Prevention and environmental control

"Homework"

\section{Session 4}

Maintaining a health care relationship

Exercise and asthma

Review of MDI technique

Management of acute asthma episodes using the Asthma Action Plan
Figure 1. Outline of the peak flow educational program, indicating differences between the symptom monitoring (SM) and symptom plus peak flow monitoring (PFM) program. All three versions covered these topics in four weekly $2-\mathrm{h}$ sessions. BID = twice daily; MDI = metered dose inhaler; PRN = as needed. 


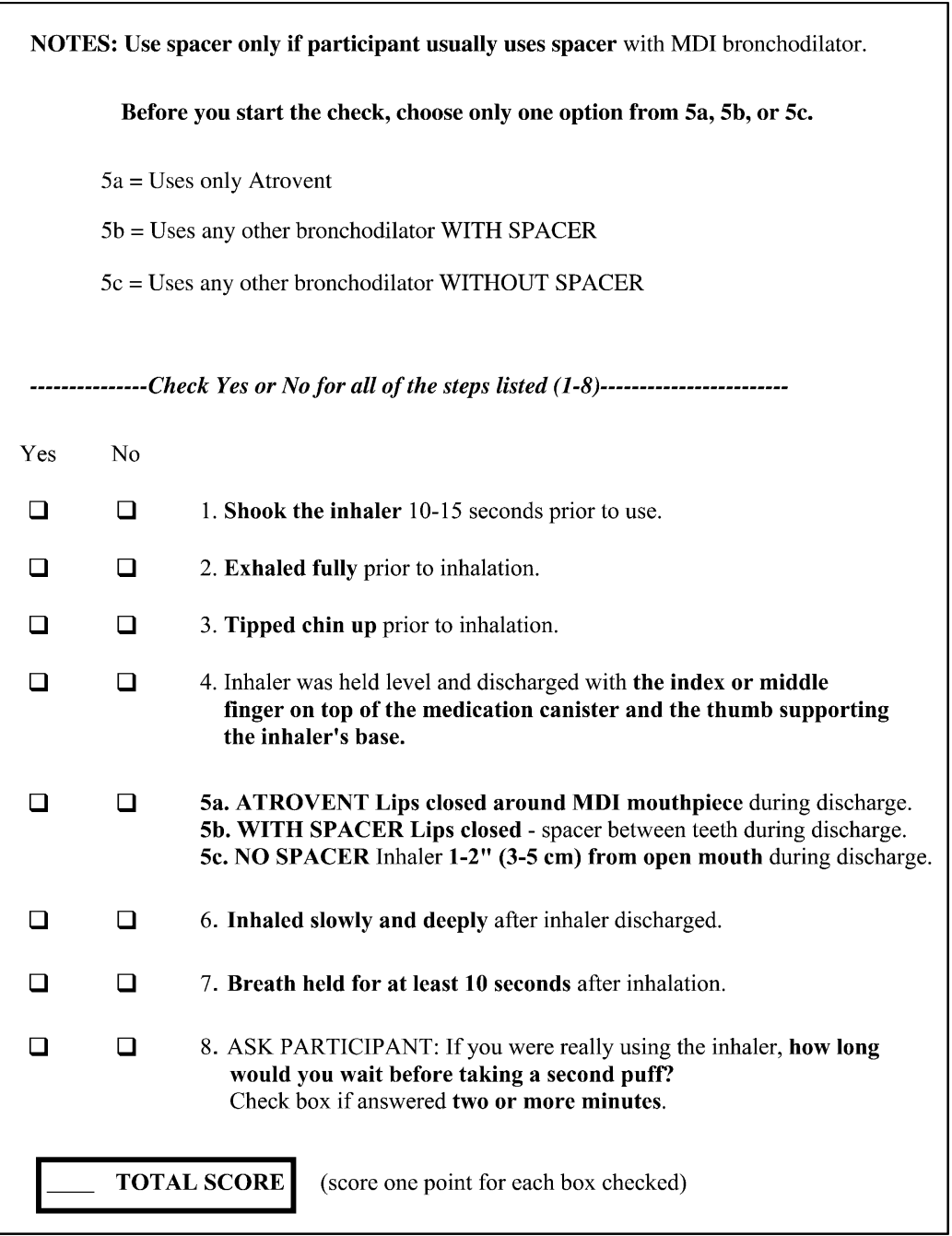

Figure 2. MDI technique performance checklist.

for a 1-d period is shown in Figure E2 of the online supplement. A complete diary is available from the corresponding author.

\section{Intervention Compliance Measures}

We determined the proportion of participants who returned diaries in each month of follow-up, as well as the proportion of days on which peak flow rates were recorded in those diaries.

\section{Outcome Measures}

Primary outcomes were HCU and asthma-specific quality of life; the secondary outcome was lung function. Follow-up clinic visits occurred every 6 mo through the 2 yr of follow-up. At these visits, we administered the Juniper Asthma Quality-of-Life Questionnaire, standardized version (AQLQ/S) (33), and the generic Short Form-36 (SF-36) health status instrument (34). At each visit, we also performed spirometry, before and after two puffs of a bronchodilator, using standardized methods (30).

We abstracted HCU data from clinical databases for the year before and $2 \mathrm{yr}$ after randomization. Visits were classified as hospital or emergency department care, other acute care (including urgent and afterhours care), or nonacute care.

\section{Statistical Analyses}

We used SAS software, version 6.12, for all analyses (SAS Institute, Inc., Cary, NC). Spirometric data $\left(\mathrm{FEV}_{1}\right)$ are expressed as \% predicted (35) for tabular presentation, but our analyses modeled absolute $\mathrm{FEV}_{1}$ and included age, height, age squared, and an age-height interaction term as covariates. We used generalized estimating equations (36) to fit linear models that predicted baseline and postrandomization out- comes as a function of treatment group (SM vs. PFM) and time. Interactions between treatment group and time were used to test the primary hypothesis of no intervention effect. A logistic model was used for proportions, whereas analyses of other outcomes assumed normality. Per design, participants in the twice-daily and as-needed arms (the PFM subgroups) were combined for the primary analyses. We used repeatedmeasures analysis of variance to determine the effects of time (instruction), sex, age, and their interactions on pressurized MDI use scores.

\section{RESULTS}

Figure 3 summarizes the participant flow during study recruitment, intervention, and retention. Of those identified from administrative records as being in the right age range and having been seen for asthma, and who were contactable $(n=2,524)$, $1,254(49.7 \%)$ agreed to be screened for eligibility. Of these, 834 (33.0\%) proved ineligible at phone screening and 124 (29.5\%) of 420 tested did not meet lung function criteria, including sufficient reversibility. The remaining 296 were eligible and were enrolled and randomized.

\section{Baseline Characteristics}

Table 1 presents the baseline characteristics of participants in the SM and PFM groups. Participants in the two treatment arms were generally similar, although a higher proportion of the SM group had smoked in the past or were current smokers, and they reported a greater number of pack-years of smoking. Overall, $63 \%$ were ever-smokers; only $5 \%$ were current smokers at the 


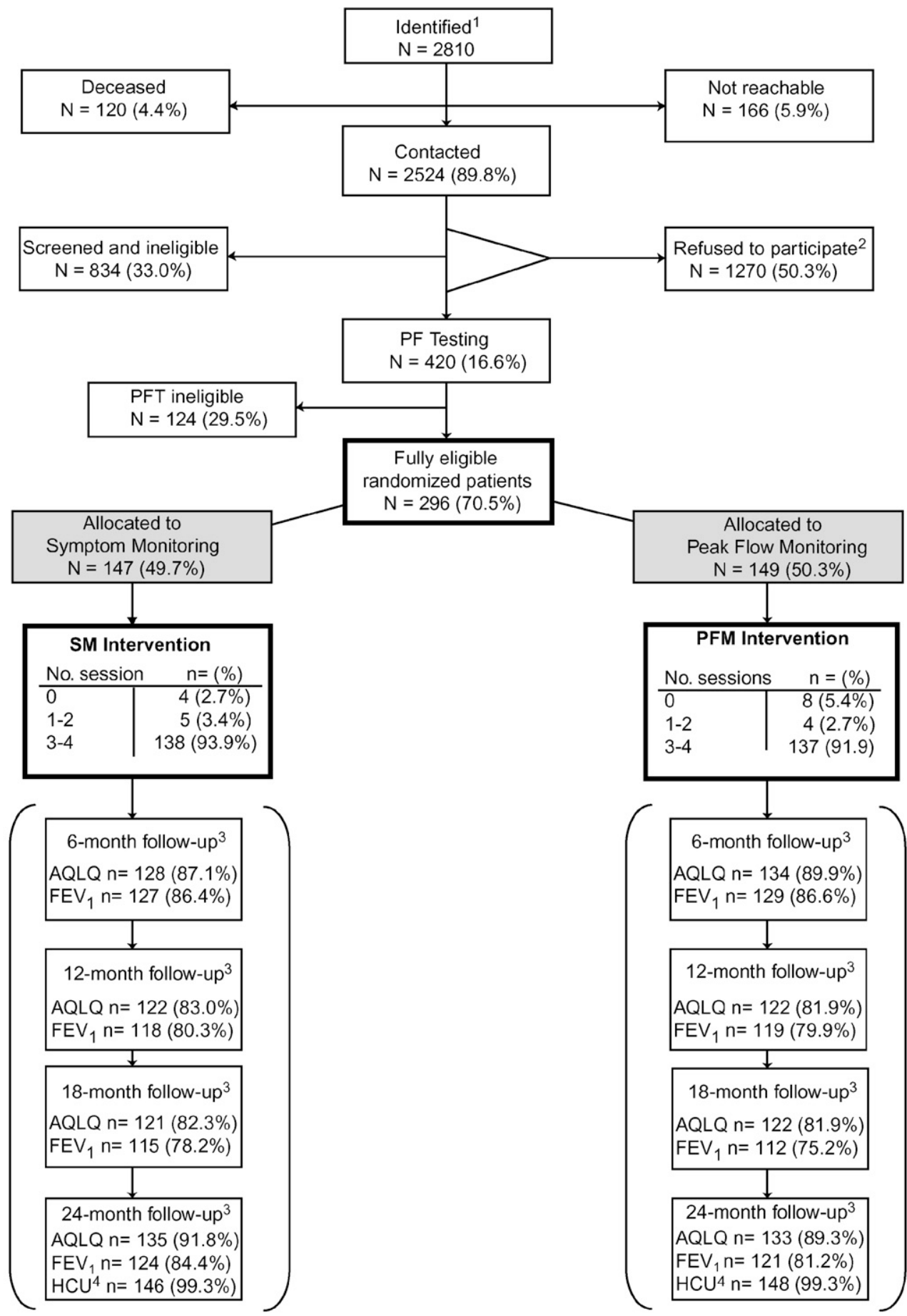

1. In age range and seen for asthma

2. Refused either screening, assessment or other participation. Reasons: inconvienence: 480 (37.8\%); age/illness: 203 (16.0\%); no benefit perceived/other: $234(18.4 \%)$; no reason given: $353(27.8 \%)$.

3. $\mathrm{MDI}$ performance checklist data at successive follow-ups: 6 mos. $\mathrm{N}=245 ; 12$ mos. $\mathrm{N}=237 ; 18 \mathrm{mos}$. $\mathrm{N}=226 ; 24$ mos. $\mathrm{N}=241$.

4. $91.9 \%$ of randomized patients had a full 24 mos. of Kaiser Health Plan membership and hence utilization data. Only one individual allocated to each experimental condition had less than the minimum of 6 mos. of membership set as the criterion for analysis.

Figure 3. Progress of cases in peak flow study.

time of the study. Participants ranged in age from 50 to $92 \mathrm{yr}$, with a mean age of $66 \mathrm{yr}$. Just over half of participants were women, and $94 \%$ were white, not of Hispanic origin. More than $93 \%$ reported atopic symptoms. Reported inhaled corticosteroid use was high $(90 \%)$, and $62 \%$ of participants reported using at least two breathing medications daily. Mean prebronchodilator $\mathrm{FEV}_{1}$ was $59 \%$ of predicted, and the mean change in $\mathrm{FEV}_{1}$ in response to albuterol was $17.1 \%$. Comorbidities were common in this population: $62 \%$ of patients had at least one comorbidity. Mean levels of baseline quality-of-life/health status were similar 
TABLE 1. BASELINE CHARACTERISTICS OF STUDY PARTICIPANTS

\begin{tabular}{|c|c|c|c|}
\hline & $\begin{array}{l}\text { Symptom Monitoring } \\
\qquad(n=147)\end{array}$ & $\begin{array}{l}\text { Peak Flow Monitoring } \\
\qquad(n=149)\end{array}$ & $\begin{array}{c}\text { Total } \\
(n=296)\end{array}$ \\
\hline Female sex, \% & 52 & 52 & 52 \\
\hline White/non-Hispanic race, $\%$ & 94 & 95 & 94 \\
\hline Age, mean, yr (SD) & $66(9.2)$ & $66(9.6)$ & $66(9.4)$ \\
\hline Asthma duration, median, yr (IQR) & $20(11-42)$ & $19(10-48)$ & $20(10-44)$ \\
\hline \multicolumn{4}{|l|}{ Smoking status, \% } \\
\hline Never-smoker & 33 & 41 & 37 \\
\hline Current smoker & 7 & 3 & 5 \\
\hline Ex-smoker & 59 & 56 & 57 \\
\hline Pack-years of smoking, median (IQR)* & $19(0-41)$ & $4(0-35)$ & $9(0-38)$ \\
\hline Prevalence of atopic symptoms, ${ }^{\dagger} \%$ & 93 & 94 & 93 \\
\hline Daily inhaled corticosteroid use, \% & 90 & 89 & 90 \\
\hline No. daily breathing meds, median (IQR) & $2(0-6)$ & $2(0-6)$ & $2(0-6)$ \\
\hline No. comorbidities, ${ }^{\ddagger}$ median (IQR) & $1(0-4)$ & $1(0-5)$ & $1(0-5)$ \\
\hline Prealbuterol $\mathrm{FEV}_{1}$, mean, $\%$ predicted (SD) & $58.5(22.0)$ & $59.4(21.7)$ & $58.9(21.8)$ \\
\hline$\%$ Change in $\mathrm{FEV}_{1}$ in response to albuterol & $16.3(12.6)$ & $17.1(20.4)$ & $17.1(17.0)$ \\
\hline
\end{tabular}

for the two groups. Information was not obtained on patient's ethnicity, level of education, or income. However, various Kaiser internal studies have shown that its patient population is generally representative of the communities in which it is located, with the exception that persons in the highest and lowest socioeconomic levels are underrepresented.

\section{Follow-up Visits}

Attendance at the 6-, 12-, 18-, and 24-mo follow-up visits was $89,82,82$, and $89 \%$, respectively. Follow-up rates were similar in the two groups.

\section{Intervention Compliance}

Approximately $93 \%$ of participants attended three or more sessions (93.9\% in SM and 91.9\% in PFM groups). Participants in both treatment groups were asked to maintain monthly diaries, which they turned in to clinical research center staff at the end of each month. Return of these diaries gradually declined over time, from $89 \%$ in the twice-daily group and $71 \%$ in the asneeded and SM groups in the first month postintervention to about $61 \%$ in all three groups after 14 mo. For participants in the twice-daily arm of the PFM group, all of whom were asked to use their peak flow meters on a daily basis throughout the study, peak flow rates were recorded in returned diaries, on average, $85 \%$ of days in the first month and $55 \%$ of days in Month 14. The as-needed participants recorded peak flow rates, on average, $52 \%$ of days in the first month and $41 \%$ of days in Month 14. Assuming no diary use among those who did not return diaries, we conservatively estimate that $76 \%$ of twicedaily and $37 \%$ of as-needed participants were recording peak flow information during the first month and 34 and $25 \%$, respectively, were doing so at 14 mo.

\section{Technique}

At baseline, participants exhibited poor MDI technique (Figure 4). The mean score for the total sample was 4.0 on a scale from 0 to $8(\mathrm{SD}=2.0)$. Before instruction, only $13 \%$ of participants could correctly demonstrate seven or all eight elements of proper technique. Scores showed a symmetric distribution across all possible values, from 0 (no steps done correctly, $3 \%$ of participants) to 8 (all steps done correctly, 3\%).
The most common errors were as follows: not waiting a sufficient time between successive puffs (78\%), using inappropriate mouth position when using (or not using) a spacer (67\%), and not shaking the inhaler sufficiently (63\%; Figure 4, table). Postinstruction MDI performance data were available on $83,80,76$, and $81 \%$ of the participants at the successive follow-up assessments. At 6 mo, performance was dramatically better than it had been at baseline (median $=7$, interquartile range $=6-8$ ). This improved performance was maintained at each subsequent assessment. The increase from baseline to 24 mo was highly significant $(\mathrm{p}=0.0001)$. At all four postinstruction assessments $(6,12,18$, and $24 \mathrm{mo}), 95 \%$ of participants scored 5 or greater, and $64,79,81$, and $83 \%$, respectively, scored 7 or 8 . This can be compared with preinstruction rates of $40 \%$ scoring 5 or more and $13 \%$ scoring 7 or more. The residual errors at 12 mo were primarily in chin position, down slightly from 41 to $37 \%$, and not waiting a sufficient time between puffs (down dramatically from 78 to $25 \%$ ). Too rapid an inhalation was still a problem for $11 \%$ of participants, but $5 \%$ or less made other errors.

Men and women exhibited similar MDI technique at baseline and showed similar improvements over time (Table 2). Significant MDI improvements were also seen in both younger (ages 50-64 yr) and older participants, with the older participants showing significantly greater improvement over time (presumably because of their initially poorer technique). These results were confirmed by repeated-measures analysis of variance.

No significant differences in MDI skill were associated with the two monitoring conditions-symptoms alone (SM) or symptoms plus peak flow either as needed or twice daily-either initially or in terms of the degree of improvement postinstruction. This was as expected, because MDI instruction was identical for patients assigned to both the SM and PFM self-monitoring conditions.

\section{Health Outcomes}

$H C U$. Table 3 shows the rate of various categories of asthma $\mathrm{HCU}$ for the year before randomization and for the $2 \mathrm{yr}$ postrandomization. Although the components of total acute care are presented for information purposes, formal statistical testing was limited to total acute care, total nonacute care, and total care. 


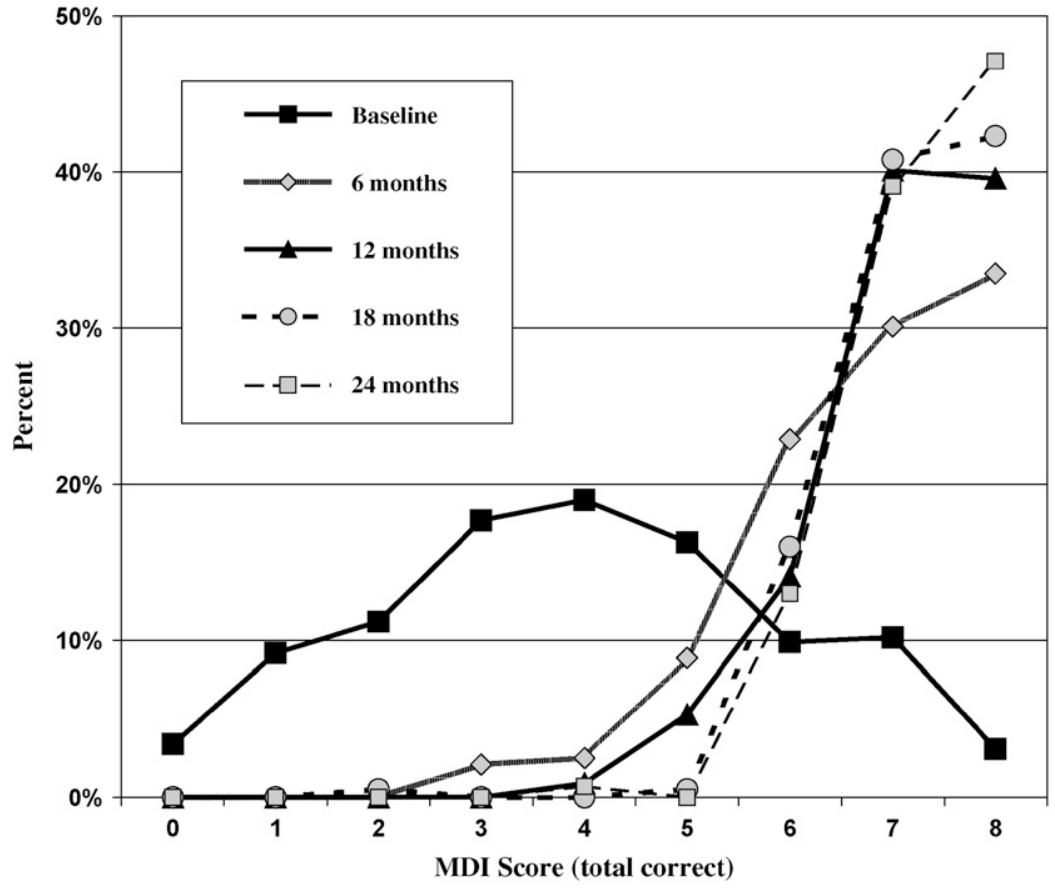

\begin{tabular}{|l|r|r|}
\hline \multicolumn{1}{|c|}{ Checklist item } & \multicolumn{2}{|c|}{ N (\%) errors } \\
\hline Shook inhaler & $\begin{array}{l}\text { Baseline } \\
\text { (N=294) }\end{array}$ & $\begin{array}{c}\text { 12 mo.Follow-up } \\
\text { (N=237) }\end{array}$ \\
\hline Exhaled fully & $184(62.58 \%)$ & $12(5.06 \%)$ \\
\hline Chin horizontal & $148(50.34 \%)$ & $4(1.69 \%)$ \\
\hline Inhaler held level & $121(41.16 \%)$ & $87(36.71 \%)$ \\
\hline Mouth technique appropriate & $43(14.63 \%)$ & $1(0.42 \%)$ \\
\hline Inhaled slowly and deeply & $198(67.35 \%)$ & $9(3.80 \%)$ \\
\hline Breath held sufficiently long & $100(34.01 \%)$ & $27(11.39 \%)$ \\
\hline Wait 2 minutes between puffs & $159(54.08 \%)$ & $13(5.48 \%)$ \\
\hline
\end{tabular}

Figure 4. Percentage of participants achieving MDI performance checklist total scores (0-8) at baseline and successive follow-up assessments, with percentage of errors by specific checklist item.
We found no significant differences between the two treatment arms in any of these categories of HCU for either follow-up year $(1$ or 2$)$, or for the $2 \mathrm{yr}$ combined. The differences in the rates of nonacute $(\mathrm{p}=0.077)$ and total $(\mathrm{p}=0.087)$ asthma HCU approached statistical significance in Year 1, with the PFM patients tending to have more nonacute visits. Overall, total acute asthma HCU decreased slightly, but not significantly, in Year 1 compared with baseline and increased to a near-baseline level in Year 2. The rate of nonacute asthma visits increased,

TABLE 2. METERED DOSE INHALER PERFORMANCE CHECKLIST TOTAL SCORES

\begin{tabular}{cccccc}
\hline & Baseline & $6 \mathrm{mo}$ & $12 \mathrm{mo}$ & $18 \mathrm{mo}$ & $24 \mathrm{mo}$ \\
\hline Sex & & & & & \\
Female & $3.9(2.0)$ & $6.7(1.2)$ & $7.0(0.9)$ & $7.3(0.9)$ & $7.2(0.8)$ \\
& 152 & 136 & 130 & 123 & 133 \\
Male & $4.1(2.0)$ & $6.9(1.2)$ & $7.2(0.9)$ & $7.1(0.8)$ & $7.4(0.8)$ \\
& 142 & 109 & 107 & 103 & 108 \\
Age, yr & & & & & \\
$50-64$ & $4.4(2.1)$ & $7.0(1.0)$ & $7.2(0.9)$ & $7.3(0.8)$ & $7.5(0.7)$ \\
& 138 & 120 & 114 & 107 & 120 \\
$65+$ & $3.6(1.8)$ & $6.6(1.3)$ & $7.0(0.9)$ & $7.1(0.9)$ & $7.1(0.8)$ \\
& 156 & 125 & 123 & 119 & 121 \\
Total & $4.0(2.0)$ & $6.8(1.2)$ & $7.1(0.9)$ & $7.2(0.8)$ & $7.3(0.8)$ \\
& $(295)$ & $(245)$ & $(237)$ & $(226)$ & $(241)$ \\
\hline
\end{tabular}

Data shown as mean (SD), sample size. relative to baseline, by 0.4 visits per person-year in the first year postrandomization (95\% confidence interval [CI], 0.13, 0.67 visits/yr; $p=0.004)$. However, the nonacute visit rate returned nearer to baseline levels in Year 2, with an average increase of only 0.1 visits per year relative to baseline $(p=0.56)$. The total number of asthma visits mirrored this pattern, increasing by 0.35 visits per person-year over baseline in the first year postrandomization $(\mathrm{p}=0.019)$, but only by 0.1 visits per person-year over baseline in Year 2 postrandomization $(\mathrm{p}=0.61)$.

Quality of life. Overall, the AQLQ/S scores increased an average of 0.4 units $(95 \% \mathrm{CI}, 0.3,0.5 ; \mathrm{p}<0.0001)$ from baseline to the first (6-mo) follow-up and remained at that level subsequently (not shown). These increases did not differ significantly between the two treatment groups, however. The proportion of patients who achieved an increase of greater than 0.5 in their AQLQ score between baseline and the 6-mo follow-up was $39.1 \%$ overall (38.7\% in the PFM and $39.4 \%$ in the SM group). The proportion with a decrease of greater than 0.5 in that interval was $10.2 \%$ (12.3 and $8.25 \%$ in the two groups, respectively). The number of participants whose scores increased by more than 0.5 was significantly different from the number whose scores decreased by more than 0.5 , whereas equal numbers would have been expected by chance $\left(\chi^{2}=36.26\right.$, df $=2$, p $\left.<0.0001\right)$. This pattern remained generally the same for comparisons between baseline and each of the successive assessment points, indicating that the improvements at 6 mo were maintained subsequently. These results are consistent with the findings reported from the 
TABLE 3. MEAN RATES* OF ACUTE AND NONACUTE ASTHMA-RELATED HEALTH CARE UTILIZATION IN THE BASELINE AND 2 FOLLOW-UP YEARS

\begin{tabular}{|c|c|c|c|}
\hline Time Period & $\begin{array}{l}\text { Symptom } \\
\text { Monitoring } \\
(n=147)\end{array}$ & $\begin{array}{l}\text { Peak Flow } \\
\text { Monitoring } \\
(n=149)\end{array}$ & p Value \\
\hline \multicolumn{4}{|l|}{ ED/hospital care } \\
\hline Baseline $^{\dagger}$ & $0.10(0.52)$ & $0.13(0.46)$ & 0.65 \\
\hline Year $1^{\ddagger}$ & $0.03(0.22)$ & $0.10(0.46)$ & 0.15 \\
\hline Year $2^{\ddagger}$ & $0.14(0.58)$ & $0.10(0.41)$ & 0.52 \\
\hline Years 1 and 2, baseline & -0.02 & -0.04 & 0.68 \\
\hline \multicolumn{4}{|l|}{ Other acute care } \\
\hline Baseline $^{\dagger}$ & $0.05(0.24)$ & $0.05(0.24)$ & 0.98 \\
\hline Year $1^{\ddagger}$ & $0.06(0.23)$ & $0.04(0.23)$ & 0.59 \\
\hline Year $2^{\ddagger}$ & $0.01(0.12)$ & $0.05(0.22)$ & 0.09 \\
\hline Years 1 and 2, baseline & -0.01 & -0.00 & 0.73 \\
\hline \multicolumn{4}{|l|}{ Total acute care } \\
\hline Baseline $^{\dagger}$ & $0.15(0.60)$ & $0.17(0.54)$ & 0.71 \\
\hline Year $1^{\ddagger}$ & $0.09(0.33)$ & $0.14(0.52)$ & 0.36 \\
\hline Year $2^{\ddagger}$ & $0.15(0.64)$ & $0.15(0.47)$ & 0.97 \\
\hline Years 1 and 2, baseline & -0.03 & -0.04 & 0.85 \\
\hline \multicolumn{4}{|l|}{ Total nonacute care } \\
\hline Baseline $^{\dagger}$ & $1.31(2.34)$ & $1.12(2.20)$ & 0.47 \\
\hline Year $1^{\ddagger}$ & $1.47(1.93)$ & $1.76(2.24)$ & 0.23 \\
\hline Year $2^{\ddagger}$ & $1.35(1.97)$ & $1.24(1.82)$ & 0.61 \\
\hline Years 1 and 2, baseline & 0.18 & 0.38 & 0.42 \\
\hline \multicolumn{4}{|l|}{ Total asthma care } \\
\hline Baseline $^{\dagger}$ & $1.46(2.53)$ & $1.30(2.39)$ & 0.56 \\
\hline Year $1 \ddagger$ & $1.56(2.00)$ & $1.90(2.44)$ & 0.19 \\
\hline Year $2^{\ddagger}$ & $1.50(2.23)$ & $1.39(1.98)$ & 0.64 \\
\hline Years 1 and 2, baseline & 0.16 & 0.34 & 0.48 \\
\hline
\end{tabular}

Values shown are mean (SD).

* Rates expressed as number of events per person-year of follow-up.

${ }^{\dagger}$ One year before the date of randomization.

* Follow-up year from the date of randomization.

tests of group mean differences. Similar patterns (statistically significant overall increases that did not differ significantly between the two treatment groups) also were seen on each of the AQLQ/S subscales. The increases were 0.5 (symptom and emotional scales), 0.4 (environmental scale), and 0.3 (activity scale). No significant differences were observed between the twice-daily and as-needed subgroups within the PFM group.

The physical and mental health composite scales of the SF36 also did not differ significantly over time between the two treatment groups or between the twice-daily and as-needed PFM subgroups. On this generic health-related quality-of-life mea- sure, however, we observed no significant overall change preto postintervention, with mean changes of -0.1 and -0.2 for the mental and physical health composite scales, respectively.

Lung function. Figure 5 shows prebronchodilator $\mathrm{FEV}_{1}$ values, expressed as a percentage of the individual's predicted value, from baseline to $24 \mathrm{mo}$. Overall, prebronchodilator lung function showed a small (approximately 4 percentage points) but statistically significant increase over time for both men and women. However, there were no significant differences in these increases between the two treatment groups or between the twice-daily and as-needed subgroups.

Twelve participants died during the study; however, no adverse events were reported that were attributable to the intervention or follow-up procedures.

\section{DISCUSSION}

\section{Method of Asthma Monitoring}

The study hypothesis, that PFM would be superior to SM in terms of HCU, quality of life, and lung function, received no support from the present results. We found no difference between PFM and SM as management tools in patients $50 \mathrm{yr}$ and older with moderate-severe asthma when both were used in conjunction with a written asthma action plan and in the setting of a carefully designed, age-appropriate asthma education program. We did not perform ad hoc analyses looking for intervention effects in subgroups of patients. Such comparisons were not preplanned and the study was not appropriately powered for this purpose. We note that, given the failure to show an overall effect, any significant positive effect within any substantial-sized subgroup would have had to be offset by a detrimental effect among the remaining patients.

The lack of a significant difference between the PFM and SM groups is consistent with a growing body of literature that addresses this topic; our study contributes a similar finding specifically in older adults.

If we had elected to evaluate the differences between PFM and SM strategies and between monitoring (in general) and a nonintervention control group, a three-arm study would have been required. The total sample size would have had to be at least 450 (150/group) and potentially as large as 600 (300 in the monitoring conditions combined and an equal-sized control group). Justification of the expenditure of the substantial resources that would be required for such a study would depend

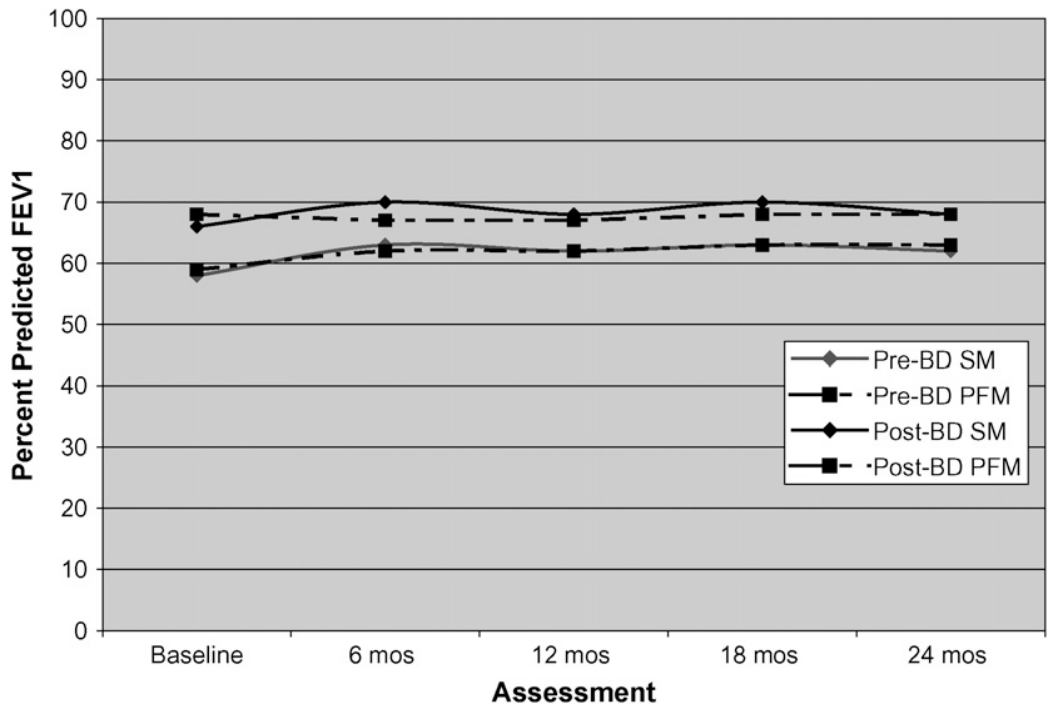

Figure 5. Lung function (\% predicted $\mathrm{FEV}_{1}$ ) at each assessment point, pre- and postbronchodilator, by group ( $\mathrm{SM}$ vs. PFM). $\mathrm{BD}=$ bronchodilator. 
on the importance attached to answering both questions in a single study. We judged the determination of the value of asthma education in adults to have been of secondary interest, because considerable evidence already exists of the value of carefully designed asthma education in adults, and specifically, of the value of the educational program from which the present intervention was adapted.

Concern about the practicality of recommending regular PFM for most patients with moderate-severe asthma prompted the NAEPP to choose PFM as one of four topics for a systematic review when the EPR-2 was updated in 2002 (11). Although five studies that compared SM and PFM have been published since the EPR-2, all have significant limitations: for example, one only included children. The most important limitation was lack of sufficient power to detect differences between the groups. In contrast, our study was adequately powered to detect moderatesized differences in the primary outcomes, and our sample size was more than double that in the recent studies (see sample size calculations in Methods).

The primary rationale for PFM comes from its relative objectivity in the assessment of lung function. Reliance on the patient's or provider's subjective assessment of symptoms can mislead diagnosis of the degree of airflow obstruction (1). Difficulty in perceiving compromised lung function has been shown to be common in patients with asthma $(21,22,37)$ and has been proposed as an important risk factor for asthma deaths. PFM also has been touted (38) as a means to enhance communication between patient and provider, thereby increasing the likelihood that the patient receives timely and appropriate care.

The fact that we, and others, have not found a difference between the two monitoring methods, when both groups have been provided with comparable education about asthma, suggests that it is the education itself, and the focus on paying attention to either symptoms or lung function as indicators of lapses in control and the need to take action, and not the method of self-monitoring that is most important (39). As proposed in the EPR 2002 update, education can help the patient "tune in" to the disease. Our finding also suggests that adults older than 65 are as capable of self-monitoring or "tuning in" as those between 50 and 65 . We were unable to isolate the behavioral change responsible for the observed improvement in quality of life and lung function in both conditions, but suggest that these improvements may be due to increased knowledge of asthma, improved adherence to medication, improved MDI technique (which we observed), or some combination of these factors. The fact that we did not find that regular PFM improved asthma outcomes does not suggest that it is not a worthwhile strategy for patients to monitor their asthma status. A compelling argument in favor of PFM is that it helps provider-patient communication, including during exacerbations, in that it provides an objective measure of function.

One of the frequent criticisms of PFM is that patients will not continue to regularly monitor their peak flow over any extended period of time, especially when they feel well. We found, however, that a reasonably large proportion of participants who were instructed to make twice-daily measurements (twice-daily group) continued to measure their peak flow regularly, if not daily. Fourteen months after the intervention, $61 \%$ still returned a monthly diary, and, on average, peak flow measurements were recorded on more than half of the days (55\%). Among those instructed to measure peak flow only when they experienced symptoms or otherwise felt a need to do so (as-needed group), the rate of diary returns was the same $(61 \%)$, but the frequency of measurement somewhat lower-after 14 mo, measurements were being recorded on $41 \%$ of the days. Arguably, even this rate of self-monitoring may be beneficial to patients. Despite the decreased compliance with PFM and diary keeping over time, patients may continue to pay attention to their symptoms. Even if they do not continue to monitor their peak flow as frequently, or keep a diary, patients may continue to monitor their symptoms. This may be a logical development because (1) both groups were taught to monitor symptoms as well as peak flow and (2) for older patients, many of whom have some degree of fixed obstruction, peak flow may not change appreciably from day to day. Hence, they may have low motivation for frequent monitoring. The need to maintain a diary on a regular basis for an indefinite period may also be questioned once patients become familiar with the signs of worsening asthma. However, the fact that the patients have learned their personal best and typical peak flow rates may give them a good basis for measuring and evaluating their peak flow should they begin to experience symptoms.

\section{Changes between Baseline and Follow-up in Both Experimental Groups}

For purposes of determining whether PFM had benefits beyond those due to self-management education, which includes SM, the SM condition was the appropriate control group. Some previous studies have been informative because they compared selfmanagement education including PFM with an untouched (no education) control. However, the fact that we did not include an untouched (no education) control as a third arm in the present study means that some caution is required in interpreting the changes that were observed between baseline and 6 mo (and sustained thereafter) in both PFM and SM groups. To include this additional control condition would have required at least an additional 150 participants. The additional investment of resources was not judged to be warranted. It is possible that intrinsic factors, other than the education, self-monitoring, action plan, and so forth that were common to the PFM and SM protocols, produced the observed changes. That some external change was responsible (e.g., a change in asthma management practices in this health care system) appears unlikely in that the changes were manifested within the first 6 mo postrandomization for patients randomized successively over a period of 11 mo. Furthermore, these changes are consistent with the benefits reported for other comprehensive asthma self-management education programs. Devine (39) conducted a meta-analysis of 15 studies evaluating asthma self-management programs for adults, the majority of which were randomized controlled trials. Examining the pooled, unbiased, mean effect sizes (i.e., the differences between education and control group scores in SD units), they concluded that education can significantly improve self-management, psychologic wellbeing, and functional status, and can reduce attack frequency and $\mathrm{HCU}$, but that improvements in pulmonary function and peak flow have been smaller and less consistently observed.

\section{Inhaler Technique}

Both the PFM and SM control in the present study showed significant improvements in MDI technique for older, even elderly, adults. This was achieved with a modest investment of professional time by (1) providing a spacer and (2) engaging in a planned process of explanation, demonstration, detailed assessment, and coaching. The improvement was well maintained over a 2 -yr period, at least when participants were periodically reassessed during the interim and given corrective feedback, which is the NAEPP expert panel's recommendation. A significant age-related difference in initial performance was observed, but no significant sex-related difference; after instruction, no significant age- or sex-related differences were found. These findings also demonstrate that proper use of MDIs can be taught 
successfully, including to older adults, and suggest the generalization that achieving proper use of newer devices with less potential for inadequate dosing in older adults should be possible and perhaps even more readily achieved than for MDIs. Arguably, correct MDI technique is becoming less important for improvement of asthma control because other delivery devices for asthma controller medications, such as inhalation-triggered, dry powder devices, are available. However, MDIs are still used for short-acting bronchodilators and are the most available and heavily used inhaled medications in many parts of the world. Consequently, the "trainability" of patients in the correct use of MDIs is still relevant and important. Furthermore, the newer devices pose their own difficulties and confusions for patients $(40,41)$. Our demonstration that older adults of both sexes can successfully master MDI technique should encourage efforts to ensure correct use of all devices for delivery of asthma medications in this age group.

We conclude that men and women older than 50 exhibit clinically important and readily observable deficiencies in selfadministration of MDI medications in the absence of careful instruction, a deficiency that is even more pronounced in those older than 65 . We also found that these individuals can acquire and retain appropriate technique, as judged by observed performance, including all of the elements most critical for adequate deposition in the lower respiratory tract. Some patients clearly required, and were given, more coaching than others. However, even those who did not achieve optimal technique during the initial instructional sessions eventually did so with periodic assessment and feedback.

\section{Quality of Life}

Asthma-specific quality of life improved equally in both groups, and this improvement was sustained over the 2-yr follow-up. Lung function also improved in both groups over this time period. General health status, as assessed by the SF-36, and asthmarelated HCU did not change significantly in either group, with the exception of a significant transitory increase in nonacute asthma HCU in the first follow-up year. This increase may reflect the fact that both educational programs encouraged patients to see their physician to confirm or adjust their regular preventive care, especially when it appeared the regimen might warrant reevaluation, and not to see the physician only for crisis management. Given the very low rate of medical visits for nonacute care in this population in the baseline period ( $49 \%$ had not seen their physician for any nonacute care in the previous year), it is very likely that these additional visits were appropriate.

\section{Lung Function}

Lung function was chosen as a secondary outcome in this study, largely because we believed that HCU and asthma-specific quality of life were more meaningful outcomes, especially in older adults who may have some degree of remodeling and less reversibility. However, we found that lung function showed a small but statistically significant increase from baseline, with, again, no significant difference in improvement between experimental groups. The small improvement may have been attributable to closer monitoring and appropriate response to symptoms or changes in peak flow rate, to better inhaler use technique, to closer attention to regular use of controller medications, or to other changes made in response to the education that was provided. Others have also reported that lung function was not improved as a result of a self-management education program $(6,7)$; improvement was seen in two studies $(5,8)$. The rate of lung function decline in those with asthma is, on average, slightly faster than in those without asthma, and is accelerated even more in those who have asthma and are current or past smokers
(42). Furthermore, the age-related rate of lung function decline tends to accelerate with age, and would be expected to be faster in the present age group than in younger adults. If this is the case, our results showing a small improvement in lung function may not reveal the full clinical benefit-namely, a slowing of the rate of the normally expected decline in lung function that would otherwise have been observed. Without an untouched control group, however, we cannot be sure that this is the case.

Our finding that asthma-specific quality of life and lung function improved significantly in both groups at the first (6-mo) follow-up, but not at baseline, and was sustained throughout the follow-up is potentially important. An increase was seen in all of the domains of asthma-related quality of life-activity, emotional, environmental, and symptoms. The overall health status of our study population at baseline, at least as measured by the AQLQ and SF-36, was relatively good, considering the severity of their asthma, their age, their smoking history, and the number of comorbidities they reported. The mean overall score for the AQLQ at baseline was 5.05, which is slightly above the midpoint on the asthma-specific AQLQ/S scales, each of which ranges from a low of 1 to a high of 7 . The mean scores increased 0.4 units at the first follow-up visit, and this improvement was maintained over the 2-yr follow-up.

\section{HCU}

Our rates of $\mathrm{HCU}$ were relatively low prior to the intervention, making it difficult to infer much about the effects of our intervention on utilization. Nevertheless, our finding that there were decreases in acute HCU for asthma, albeit small and nonsignificant, is in agreement with other educational intervention studies. In contrast, total nonacute asthma care increased slightly. Both changes, although not statistically significant, were in the appropriate directions. The EPR-2 recommends at least annual outpatient visits for all patients with asthma, with more frequent visits for those with more control problems (1). Only $51 \%$ of our study population had had any nonacute asthma care for the year before enrolling in the study. This increased to $61 \%$ during the first year after the education program, then fell to $55 \%$ in the second year. Although these proportions do not include those who may have received care for their asthma in the course of a medical visit for another purpose, if their provider did not list asthma in the diagnoses for the visit, we concluded that, even when encouraged to consult their provider for regular asthma care, many patients with moderate-severe asthma do not do so.

\section{Pattern of PFM}

Asthma guidelines, such as the EPR-2, recommend regular PFM, rather than monitoring on an as-needed basis. We therefore designed the study to compare the two approaches by randomizing, within the PFM group, to twice-daily or as-needed monitoring. The twice-daily group, on average, measured their peak flow more often than the as-needed group, and this difference was maintained over the 2-yr follow-up. There was a greater dropoff in the as-needed group than in the twice-daily group, but both maintained reasonable frequencies of PFM for $2 \mathrm{yr}$. Despite the twice-daily versus as-needed differences in frequency of PFM, we found no difference in other outcomes between the two groups. We conclude from this that the frequency of PFM is less important than instruction in how to manage and monitor asthma, but that having been taught how to use a peak flow meter as part of the monitoring, a substantial proportion of patients will continue to check their peak flow, at least when they experience problems. For how many, and for which, patients this has a clinical benefit remains to be determined. 


\section{Limitations}

Our study population may have been more adherent to management recommendations than is usual among patients with asthma. The proportion who reported using inhaled corticosteroids at baseline was greater than $90 \%$. This high rate of reported "use" reflects current asthma pharmacotherapy in this health care system but does not necessarily indicate that patients' use was consistent with the prescribed level or schedule of administration. We did not obtain objective evidence with regard to medication adherence. Attendance at the classes was very high, as were the rates of PFM. Care must be taken, therefore, in extrapolating our results to the broader asthma patient population, many of whom may be less likely to follow a management plan that includes expectations of frequent monitoring.

We recognize that self-reported self-monitoring also may overestimate actual behavior. We did not have the resources to use electronic monitoring of either peak flow measurement, and no objective means exists to confirm SM. We were unable to determine from patients' medical records whether they communicated with their physician regarding peak flow results, and we did not gather this information by patient report. The value of the study lies primarily in its clear findings with regard to the lack of difference in the effects of these two methods of selfmonitoring on various health outcomes.

\section{Conclusions}

The evidence from this study supports the conclusion that the method of self-management, whether SM alone or the additional use of a peak flow meter, does not differentially affect outcomes, and suggests that what is most important is that the individual regularly monitors (i.e., pays attention to or tunes in to) his or her status and understands what to do when changes occur. Both monitoring approaches are equally effective management strategies for adults older than $50 \mathrm{yr}$ with moderate-severe asthma, when introduced as part of a comprehensive education program, in terms of improved lung function and quality of life.

Conflict of Interest Statement: A.S.B. has served on advisory boards for GlaxoSmithKline (GSK), Altana, Schering Plough, and Merck. She has participated in chronic obstructive pulmonary disease (COPD) workshops funded by AstraZeneca (AZ), and GSK. She is Scientific Director for the Burden of Obstructive Lung Disease (BOLD) initiative, which receives unrestricted educational grants to the Kaiser Permanente Center for Health Research from Boehringer Ingelheim (BI), Pfizer, GSK, AZ, Novartis, Chiesi, and Merck. W.M.V. has served on ad hoc advisory boards for Merck and Co. and has participated in COPD workshops funded by Merck and GSK. He is Director of the BOLD Operations Center, funding for which includes unrestricted educational grants to Kaiser Permanente Center for Health Research from BI, Pfizer, Altana, GSK, AZ, Novartis, Chiesi, and Merck. S.R.W. does not have a financial relationship with a commercial entity that has an interest in the subject of this manuscript. E.A.F. does not have a financial relationship with a commercial entity that has an interest in the subject of this manuscript. A.D.H. does not have a financial relationship with a commercial entity that has an interest in the subject of this manuscript.

Acknowledgment: The authors thank the staff in the Recruitment, Research Clinic, Health Education, Programming, and Research Analyst departments at the Kaiser Permanente Center for Health Research for their invaluable assistance, and the participants who gave their time so generously.

\section{References}

1. National Asthma Education and Prevention Program; National Heart, Lung, and Blood Institute; National Institutes of Health. Guidelines for the diagnosis and management of asthma. Asthma Expert Panel Report 2. Bethesda, MD: National Institutes of Health; 1997. Publication No. NIH 97-4051.

2. Gibson PG, Coughlan J, Wilson AJ, Abramson M, Bauman A, Hensley MJ, Walters EH. Self-management education and regular practitioner review for adults with asthma. Cochrane Database Syst Rev 2000;97(2): CD001117.

3. Charlton IH, Charlton G, Broomfield J, Mullee MA. Evaluation of peak flow and symptoms only self management plans for control of asthma in general practice. BMJ 1990;301:1355-1359.
4. GRASSIC (Grampian Asthma Study of Integrated Care). Effectiveness of routine self monitoring of peak flow in patients with asthma. BMJ 1994:308:564-567.

5. Ignacio-Garcia JM, Gonzales-Santos P. Asthma self-management education program by home monitoring of peak expiratory flow. Am J Respir Crit Care Med 1995;151:353-359.

6. Jones KP, Mullee MA, Middleton M, Chapman E, Holgate ST. Peak flow based asthma self-management: a randomised controlled study in general practice. Thorax 1995;50:851-857.

7. Lahdensuo A, Haahtela T, Herrala J, Kava T, Kiviranta K, Kuusisto P, Peramaki E, Poussa T, Saarelainen S, Svahn T. Randomised comparison of guided self-management and traditional treatment of asthma over one year. BMJ 1996:312:748-752.

8. Turner MO, Taylor D, Bennett R, Fitzgerald M. A randomized trial comparing peak expiratory flow and symptom self-management plans for patients with asthma attending a primary care clinic. Am J Respir Crit Care Med 1998;157:540-546.

9. d'Souza WJ, Burgess C, Ayson M, Crane J, Pearce N, Beasley R. Trial of a "credit card" asthma self-management plan in a high-risk group of patients with asthma. J Allergy Clin Immunol 1996;97:1085-1092.

10. Gibson PG, Coughlan J, Wilson AJ, Hensley MJ, Abramson M, Bauman A, Walters EH. Limited (information only) patient education programs for adults with asthma. Cochrane Database Syst Rev 2000;97(2): CD001005

11. National Asthma Education and Prevention Program. Expert panel report: guidelines for the diagnosis and management of asthma update on selected topics-2002. J Allergy Clin Immunol 2002;110:S141-S219.

12. Chowienczyk PJ, Parkin DH, Lawson CP, Cochrane GM. Do asthmatic patients correctly record home spirometry measurements? BMJ 1994; 309:1618.

13. Chmelik F, Doughty A. Objective measurement of compliance in asthma treatment. Ann Allergy 1994;73:527-532.

14. Reeder KP, Dolce JJ, Duke L, Raczynski JM, Bailey WC. Peak flow meters: are they monitoring tools or training devices? J Asthma 1990; 27:219-227.

15. Verschelden P, Cartier A, L'Archeveque J, Trudeau C, Malo JL. Compliance with and accuracy of daily self-assessment of peak expiratory flows (PEF) in asthmatic subjects over a three-month period. Eur Respir J 1996;9:880-885.

16. Côté J, Cartier A, Malo JL, Rouleau M, Boulet L-P. Compliance with peak expiratory flow monitoring in home management of asthma. Chest 1998;113:968-972.

17. Marks GB, Burney PGJ, Premaratne UN, Simpson J, Webb J. Asthma in Greenwich, UK: impact of the disease and current management practices. Eur Respir J 1997;10:1224-1229.

18. Van Ganse E, Leufkens HGM, Vincken W, Hubloue I, Bartsch P, Bouckaert A, Ernst P. Assessing asthma management from interviews of patients and family physicians. J Asthma 1997;34:203-209.

19. Jain P, Kavuru MS, Emerman CL, Ahmad M. Utility of peak expiratory flow monitoring. Chest 1998;114:861-876.

20. Kendrick AH, Higgs CM, Whitfield MJ, Laszlo G. Accuracy of perception of severity of asthma: patients treated in general practice. $B M J$ 1993;307:422-424.

21. Roisman GL, Peiffer C, Lacronique JG, Le Cae A, Dusser DJ. Perception of bronchial obstruction in asthmatic patients: relationship with bronchial eosinophilic inflammation and epithelial damage and effect of corticosteroid treatment. J Clin Invest 1995;96:12-21.

22. Kikuchi Y, Okabe S, Tamura G, Hida W, Homma M, Shirato K, Takishima T. Chemosensitivity and perception of dyspnea in patients with a history of near-fatal asthma. N Engl J Med 1994;330:1329-1334.

23. Cote J, Cartier A, Robichaud P, Boutin H, Malo JL, Rouleau M, Fillion A, Lavallee M, Krusky M, Boulet LP. Influence on asthma morbidity of asthma education programs based on self-management plans following treatment optimization. Am J Respir Crit Care Med 1997;155:15091514.

24. Cowie RL, Revitt SG, Underwood MF, Field SK. The effect of a peak flow-based action plan in the prevention of exacerbations of asthma. Chest 1997;112:1534-1538.

25. Wensley D, Silverman M. Peak Flow monitoring for guided self-management in childhood asthma. Am J Respir Crit Care Med 2003;170:606-512.

26. Becket PA, Howarth PH. Pharmacotherapy and airway remodelling in asthma? Thorax 2003;58:163-174.

27. Wilson SR, Buist AS, Vollmer W, Hayward A, Sanocki L, Houston H, Oveson L. Older adults can learn and retain optimal technique in use of metered dose inhalers (MDIs) with spacers [abstract]. Am J Respir Crit Care Med 1999;159:A693. 
28. Buist AS, Vollmer WM, Sanocki LL, Wilson SR, Hayward A. Asthmaspecific quality of life in older adults with asthma following an education intervention [abstract]. Am J Respir Crit Care Med 1999;159:B693.

29. Frazier EA, Vollmer WM, Wilson SR, Hayward AD, Buist AS. Characteristics of older asthmatics with moderate-severe disease [abstract]. Am J Respir Crit Care Med 1997;155:A286.

30. Enright PL, Johnson LR, Connett JE, Voelker H, Buist AS. Spirometry in the Lung Health Study 1: methods and quality control. Am Rev Respir Dis 1991;143:1215-1223.

31. Wilson SR, Scamagas P, German DF, Hughes GW, Lulla S, Coss S, Chardon L, Thomas RG, Starr-Schneidkraut NJ, Stancavage FB. A controlled trial of two forms of self-management education for adults with asthma. Am J Med 1993;94:564-576.

32. Manzella BA, Brooks CM, Richards JM Jr, Windsor RA, Soong S, Bailey WC. Assessing the use of metered dose inhalers by adults with asthma. J Asthma 1989;26:223-230.

33. Juniper EF, Guyatt GH, Ferrie PJ, Griffith LE. Measuring quality of life in asthma. Am Rev Respir Dis 1993;147:832-838.

34. RAND. RAND 36-item health survey 1.0. 1-11. 1986. Santa Monica, CA: RAND Health Sciences Program; 1992.

35. Crapo RO, Morris AH, Gardner RM. Reference spriometric values using techniques and equipment that meet ATS recommendations. Am Rev Respir Dis 1991;123:659-664.
36. Diggle PJ, Liang KY, Zeger SL. Analysis of longitudinal data. Oxford, UK: Clarendon Press; 1994.

37. Marks GB, Yates DH, Sist M, Ceyhan B, De Campos M, Scott DM, Barnes PJ. Respiratory sensation during bronchial challenge testing with methacholine, sodium metabisulphite, and adenosine monophosphate. Thorax 1996;51:793-798.

38. Mendenhall AB, Tsien AY. Evaluation of physician and patient compliance with the use of peak flow meters in commercial insurance and Oregon health plan asthmatic populations. Ann Allergy Asthma Immunol 2000;84(5):523-527.

39. Devine EC. Meta-analysis of the effects of psychoeducational care in adults with asthma. Res Nurs Health 1996;19:367-376.

40. van Beerrendonk I, Mesters I, Mudde AN, Tan TD. Assessment of the inhalation technique in outpatients with asthma or chronic obstructive pulmonary disease using a metered-dose inhaler or dry powder device. J Asthma 1998;35:273-279.

41. van der Palen J, Klein JJ, Schildkamp AM. Comparison of a new multidose powder inhaler (Diskus/Accuhaler) and the Turbuhaler regarding preference and ease of use. J Asthma 1998;35:147-152.

42. Lange P, Parner J, Vestbo J, Schnohr P, Jensen G. A 15-year follow-up of ventilatory function in adults with asthma. N Engl J Med 1998;339: 1194-2000. 